\title{
TEK TARAFLI KAROTIS ARTER STENOZUNDA DIABETIK RETINOPATI
}

\author{
DIABETIC RETINOPATHY IN UNILATERAL CAROTID ARTERY STENOSIS
}

\author{
Mustafa Suat ALIKMA, Erkan ÜNSAL \\ İstanbul Eğitim ve Araştırma Hastanesi, Göz Hastalıkları Kliniği, İstanbul
}

Cite this article as: Alıkma MS, Ünsal E. Diabetic Retinopathy in Unilateral Carotid Artery Stenosis. Med J SDU 2019; 26(2): 205-208.

Öz

Polikliniğimize sağ gözünde az görme şikayeti ile başvuran, anamnezinde dört yıldır tanılı tip 2 diabetes mellitus (DM) olan 59 yaşındaki kadın hasta değerlendirildi. Oftalmolojik muayenede görme keskinliği (GK) Snellen eşeline göre sağ gözde 0,15, sol gözde 0,9, göz içi basıncı her iki gözde 16 mmHg olarak saptandı. Fundus muayenesinde sağ gözde optik disk başından vitre içine uzanan proliferatif fibrovasküler yapı ile birlikte dağınık intraretinal hemorajilerin olduğu izlendi. Sol gözün fundus muayenesinde sadece dağını intraretinal hemorajilerin gözlendi. Her iki gözün fundus fotoğrafı ve fundus flourescein anjiyografisi (FFA) çekildi. Fundus muayenesinde ve FFA'da iki göz arasında diyabetik retinopati (DRP) seviyeleri farklı olduğu için hasta kalp damar cerrahisi ile konsülte edildi. Karotis arter anjiyografisinde sağ internal karotis arterde ileri derecede stenoz saptandı. Bu olgu sunumunda asimetrik tutulumlu DRP'ye eşlik eden karotis arter stenozu olan bir olguyu sunmayı amaçladık.

Anahtar Kelimeler: Diyabetik retinopati, fundus flourescein anjiyografisi, karotis arter stenozu

\section{Giriş}

Diyabetes mellitüs (DM) insülin eksikliği veya periferik dokularda insülin cevabına direnç olması ile ilgili sistemik bir hastalıktır. Hastalık karbonhidrat, lipit ve protein metabolizmasında bozukluk ve bunun neticesinde kan şekeri seviyesinin yüksek olmasını bünye-

\section{Abstract}

A 59-year-old female patient was admitted to our polyclinic with complaints of low vision in her right eye. She has type 2 diabetes mellitus for four years. Her vision acuity was 0.15 in the right eye and 0,9 in the left eye by Snellen chart. Intraocular pressure was 16 $\mathrm{mmHg}$ in both eyes. In the fundus examination of right eye, fibrovascular proliferation and intraretinal hemorrhage and in left eye intraretinal hemorrhages were seen. Fundus fluorescein angiography (FFA) was performed. FFA result was similar with fundus examination. The patient was hospitalized for cardiovascular surgery because that diabetic retinopathy severity was different between both eyes. In the carotid angiography examination, a stenosis detected in the right internal carotid artery. In this study, we aimed to present a case that has asymetric diabetic retinopathy with carotid artery stenosis.

Keywords: Diabetic retinopathy, fundus fluorescein angiography, carotid artery stenosis

sinde barındırır. Bu hastalığın etyopatogenezinde genetik veya çevresel faktörler rol oynar (1).

DM'nin komplikasyonları akut ve kronik olmak üzere iki başlık altında incelenir. Akut komplikasyonları yaşamı tehdit edebilecek düzeyde olurken, kronik komplikasyonları belirli organları ve sistemleri etkileyen

İletişim kurulacak yazar/Corresponding author: m.suatalikma@gmail.com

Müracaat tarihi/Application Date: 10.07.2018 - Kabul tarihi/Accepted Date: 11.09.2018

@C Copyright 2018 by Med J SDU - Available online at http://dergipark.gov.tr/sdutfd

@Telif Hakkı 2018 SDÜ Tıp Fak Derg - Makaleye http://dergipark.gov.tr/sdutfd web sayfasından ulaşılabilir. 
mikrovasküler veya makrovasküler komplikasyonlardır. Kardiyovasküler hastalıklar, serebrovasküler hastalıklar ve periferik damar hastalığı makrovasküler komplikasyonlar olarak sınıflandırılırken, diyabetik nefropati, diyabetik retinopati (DRP) ve diyabetik nöropati ise mikrovasküler komplikasyonlar olarak sınıflandırılmaktadır $(2,3)$.

Gözü besleyen oftalmik arter karotis arterinin ilk dalıdır. Karotis arterinde olan bir darlık veya tıkanıklık gözde hipoperfüzyona yol açabilir. Tek başına karotis arter patolojisi iskemik retinopatiye, neovasküler glokoma, oküler hipotoniye, iskemik optik nöropatiye ve katarakta yol açabilir. Hem diyabet hem de tek taraflı karotis arter darlık veya tıkanıklığının varlığında ise gözün etkilenmesi daha fazla gözlenir (4). Bu vakada bir gözde hafif non-proliferatif retinopati bulguları olan, tek taraflı karotis arter tıkanıklığı olan tarafta ise yüksek riskli proliferatif DRP olan bir olguyu sunmayı amaçladık.

\section{Olgu Sunumu:}

Polikliniğimize tek gözde az görme şikayeti ile başvuran 59 yaşında bayan hasta değerlendirildi. Hasta sağ gözünün yaklaşık dört yıldır az gördüğünü ifade etti. Hastanın alınan anamnezinde dört yıldır insüline bağımlı tip 2 DM hastalığının olduğu öğrenildi. Hasta başka bir sistemik hastalığının olmadığını ifade etti. Yapılan oftalmolojik muayenede görme keskinliği Snellen eşeline göre sağda 0,15 ve solda 0,9 olarak saptandı. Göz içi basıncı her iki gözde 16 mmHg olarak gözlendi. Yapılan biyomikroskopik muayenede her iki gözün kornea, ön kamara, iris ve lensin doğal olduğu gözlendi. Yapılan fundus muayenesinde sağ gözde optik disk başından vitre içine uzanan proliferatif fibrovasküler yapı ve yer yer intraretinal hemora-

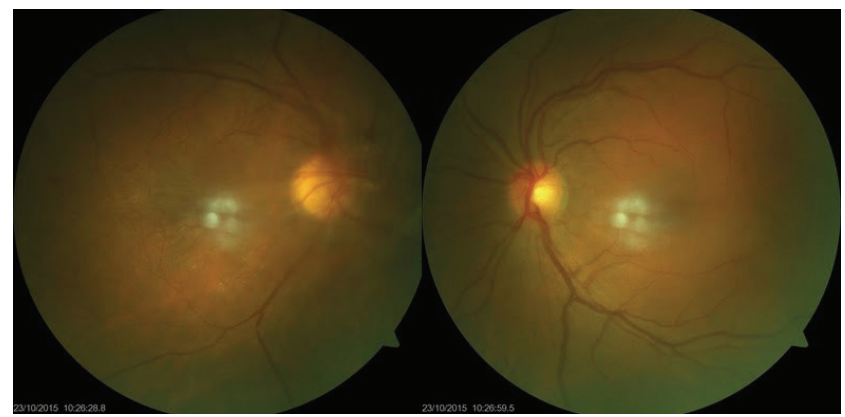

Resim 1: Fundus muayenesinde her iki göz arasında ileri derecede farklı diyabetik retinopati bulguları izleniyor. jiler gözlendi. Sol fundus muayenesinde ise yer yer intraretinal hemoraji dışında başka bir bulgu gözlenmedi (Resim 1). Hastanın fundus fotoğrafı ve fundus flourescein anjiyografisi (FFA) çekildi. Çekilen FFA'da sağ gözde yer yer mikroanevrizma ile uyumlu hiperflouresan odaklar ve optik disk başından başlayan hiperflouresan yapı izlendi (Resim 2). Sol göz FFA'da ise yer yer mikrovasküler anevrizmalar ile uyumlu bulgulara rastlanıldı (Resim 3).

Hastanın biyokimyasal değerlendirmelerinin yapılabilmesi için kan tahlili yapıldı. Laboratuvar sonuçlarında açlık kan şekerinin 157 mg/dl, Hba1c'nin \%6,8 olduğu saptandı. Karaciğer enzimleri ve renal fonksiyon değerlendirme parametrelerinin referans değerler içerisinde olduğu saptandı. Hasta endokrinoloji, kardiyoloji ve nefroloji kliniği ile konsülte edildi. Endokrinoloji kliniği açlık kan şekeri ve Hbalc seviyesinin yüksek olması nedeni ile insülin tedavi şemasını değiştirdi. Kardiyoloji kliniğinde yapılan elektrokardiyografi ve efor testlerinde hastada kardiyak bir patolojinin olmadığını belirtti. Nefroloji birimi ise hastada diyabetik nefropati olmadığını belirti.

Hastada DM hastalığının olması ve her iki gözdeki DRP seviyelerinde fark olması sebebi ile karotis arter tıkanıklığı şüphesi ile hasta kalp damar cerrahisi birimine ile konsülte edildi. Yapılan karotis arter anjiyografisinde sağ internal karotis arterde ileri derecede stenoz izlendi (Resim 4). Hastanın iki göz arasındaki DRP'nin farklı olmasının sebebi karotis arter stenozu ile ilişkilendirildi. Sağ gözde proliferatif DRP olması nedeni ile panretinal lazer fotokoagülasyon işlemi uygulandı. Hastaya tek taraflı internal karotis arter stenozu nedeni ile kalp damar cerrahisi tarafından endarterektomi uygulandı. Bu olgu sunumu için ilgili hastadan onam alındı.
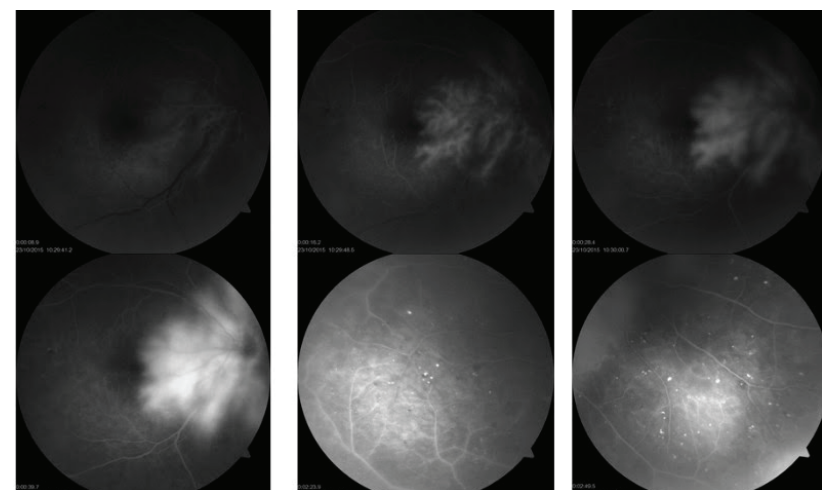

Resim 2: Sağ göz fundus flourescein anjiyografisinde optik disk başından vitreus içine uzanan fibrovasküler proliferatif doku dikkat çekmekte. 

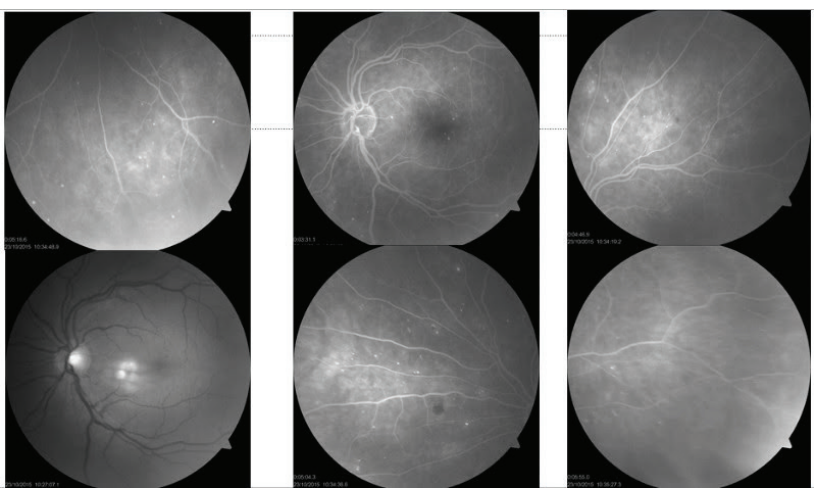

Resim 3: Sol göz fundus flourescein anjiyografisinde non-proliferatif DRP ile uyumlu bulgular izlenmekte.

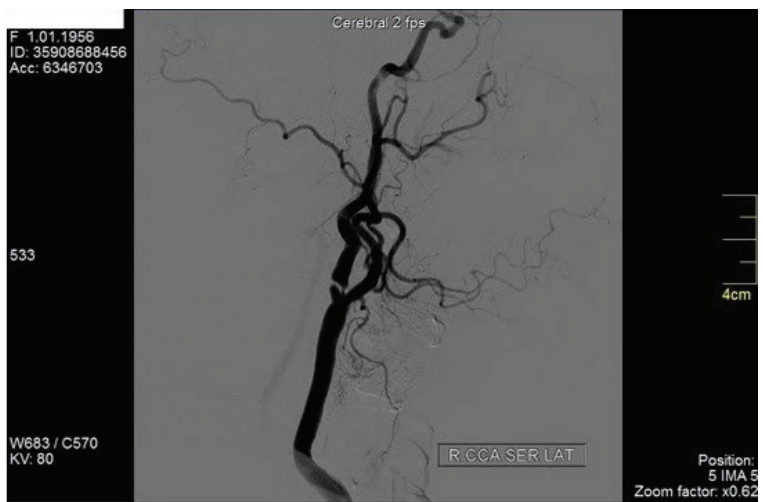

Resim 4: Çekilen karotis arter anjiyografisinde sağ internal karotis arter sisteminde stenoz gözlenmekte.

\section{Tartışma}

DRP retinanın arteriol, kapiller ve venüllerinin tutulduğu bir küçük damar hastalığıdır. Tüm dünyada önlenebilen ve tedavi edilebilen en önemli körlük neden- lerinden biridir. DM hastalarında kör olma riski genel popülasyona göre daha yüksektir (1). Bu olgu sunumunda belirtilen hastada DM'ye bağlı olarak tek gözde görme azlığı gelişmiştir.

DRP'nin klinik olarak sınıflandırılması 3 basamakıdır (Tablo 1). Preklinik fazda biyomikroskopik muayenede ve FFA'da fundus doğal olarak izlenir. Ancak yapılan elektroretinografi, renkli görme ve kontrast duyarlılık testlerinde ise bazı patolojiler saptanır. En çok izlenen DRP formu ise non-proliferatif DRP'dir. Bu formada retinal vasküler patolojiler sadece retina içerisinde sınırlı kalmaktadır. Hiperinsülinemi, insülin rezistansı ve hiperglisemi retinal kapiller yataktaki damarların destek hücresi görevini yapan perisitlerde tahribata yol açarak mikroanevrizmaların oluşmasına, damar duvar geçirgenliğini arttırarak da eksüda ve daha ileriki dönemlerde intraretinal hemorajilerin gelişmesine neden olmaktadır (1). Bu durum non-proliferatif DRP gelişimi ile ilgilidir. Bu olgu sunumundaki hastanın sol gözünde izlenen bulgular non-proliferatif DRP sınıflandırması ile uyumludur. DM hastalığının uzun dönem etkisi olan damar duvarı kalınlaşması ise damarın beslediği perifer dokuya olan kan akımı azaltır. Bunun neticesinde mevcut dokuda iskemi meydana gelir. İskemiye doku yanıtı ise VEGF sentezi şeklinde olur (5). VEGF yeni damar ve fibröz doku oluşumu ile damar geçirgenlik artışında önemli bir faktördür. Yeni damar oluşumları daha çok optik disk üzerinde ve temporal retinada gözlenir. Diyabetik hastaların vitreuslarında VEGF seviyesi, diyabetik olmayan popülasyona göre daha fazla bulunmuştur. Ayrıca proliferatif DRP'li hastalarda da vitreus VEGF düzeyinin hastalık şiddeti ile ilişkili olduğunu gösteren yayınlar mevcuttur $(5,6)$. Fibrovasküler proliferasyonun internal limitan membranın dışına çıktığı DRP sınıflandırması ise proliferatif DRP'dir $(7,8)$. Bu olgu sunumun-

\begin{tabular}{|llll|}
\hline Preklinik Faz & Nonproliferatif DRP & Proliferatif DRP & Diabetik Makulopati \\
\hline $\begin{array}{l}\text { Fundus muayene bulguları doğal } \\
\text { ancak ERG, renkli görme ve kontrast } \\
\text { görmede bozukluk }\end{array}$ & Background DRP & - Erken PDRP & - Fokal \\
& & \\
& - Hafif NPDRP & - Yüksek Riskli PDRP & - Diffüz \\
& - Orta NPDRP & - İskemik \\
& Preproliferatif DRP & - Mikst \\
& - Ağır NPDRP & \\
& - Şiddetli NPDRP & \\
\hline
\end{tabular}

DRP: Diabetik retinopati, NPDRP: Nonproliferatif diabetik retinopati, PDRP: Proliferatif diabetik retinopati. 
daki hastanın sağ gözündeki bulgular ise proliferatif DRP sınıflandırması ile uyumludur. Hastamızın tek gözünde proliferatif DRP bulguları gözlenirken, diğer gözde non-proliferatif DRP bulguları saptanmıştır. Bu olguda olduğu gibi asimetrik tutulumlu olgularda DRP seviyesini tek taraflı arttırabilen oküler iskemiye neden olabilecek sebepler araştırılmalıdır.

Gözün en önemli kanlanma kaynağı olan ve oküler iskemiye en çok yol açabilen arter sistemi karotis arter ve bu arterin ilk dalı olan oküler arterdir (4). Bu vakada sağ gözde oküler iskeminin sebebinin bulunabilmesi için kontrast madde ile karotis arterin anjiyografisi çekilmiştir. Çekilen anjiyografide internal karotis arterde ileri derecede stenoz saptanmıştır. Sağ gözde DRP seviyesinin sol göze göre daha fazla olmasının sebebi olarak internal karotis arterde saptanan stenoz suçlanmıştır.

Tek taraflı karotis arter stenozuna bağlı proliferatif DRP olan olgularda panretinal lazer fotokoagülasyon ve karotis arter endarterektomi tedavisinin hastalık progresyonunu durdurduğunu gösteren yayınlar mevcuttur $(9,10)$. Bu hastamızın sağ gözüne proliferatif DRP seviyesinin ilerlememesi için panretinal fotokoagülasyon uygulanmıştır. Kalp damar cerrahisi tarafından hastada karotis arter stenozunun tek taraflı olması nedeni ile endarterektomi uygulanmıştır. İlerleyen takiplerde hastanın sağ gözünde bulunan DRP şiddetinin artmadığı ve görme seviyesinin ilk başvurudaki gibi 0,15 seviyesinde korunduğu izlenmiştir.

\section{Sonuç}

DM'li bir hastada eşlik eden başka bir patoloji olmaz ise her iki gözdeki retinopati seviyelerinin eşit olması beklenmektedir. Ancak iskemiyi derinleştiren bir faktör bir göze etkileyip, diğer göze etki etmez ise dokuların iskemi derinlikleri ve salgılanan VEGF seviyesi farklılık gösterir. Olgumuzda olduğu gibi sağ karotis arter sisteminde olan bir tıkanlık neticesinde, hastanın sağ gözünde yüksek riskli proliferatif DRP gözlenirken, diğer gözünde ise background DRP gözlenmiştir. Bu tip olguların önemi DRP'den ziyade, eşlik eden damar tıkanıklığının hayati tehlike taşımasıdır $(11,12)$. DM hastalığı olan bireylerde her iki gözün DRP seviyeleri farklı gözlendiğinde mutlaka karotis arter sistemi incelemesi yapılması gerekmektedir.

\section{Kaynaklar}

1. Inan S. Diabetik Retinopati ve Etiyopatogenezi. Kocatepe Tıp Dergisi. 2014;15(2):207-17.

2. Marshall SM, Flyvbjerg A. Prevention and early detection of vascular complications of diabetes. BMJ : British Medical Journal. 2006;333(7566):475-80.
3. Avcı E, Çakır E. Diyabetes Mellitusun Mikrovasküler Komplikasyonu: Diyabetik Nefropati. Selçuk Tıp Dergisi. 2014;30:15-8.

4. Kocabora S, Kocabora A. Karotis Arter Hastalıklarında Göz Tutulumu. Kocaeli Tıp Dergisi. 2012;1:55-62.

5. Batıoğlu F. Diabetik Retinopati - Anti-VEGF Tedavi. Ret-Vit. 2014;22:74-8.

6. Aiello LP, Avery RL, Arrigg PG, Keyt BA, Jampel HD, Shah ST, et al. Vascular endothelial growth factor in ocular fluid of patients with diabetic retinopathy and other retinal disorders. The New England journal of medicine. 1994;331(22):1480-7.

7. Retinal Vascular Disease. Diabetic Retinopathy, American Academy of Ophthalmology - Retina and Vitreous - Section 12. 2012-2013. p. 89-112.

8. Özmert E. Diabetik Retinopati ve Makülopatinin Tanımı ve Sınıflaması. Ret-Vit. 2014;22:38-45.

9. Johnston ME, Gonder JR, Canny CL. Successful treatment of the ocular ischemic syndrome with panretinal photocoagulation and cerebrovascular surgery. Canadian journal of ophthalmology Journal canadien d'ophtalmologie. 1988;23(3):114-9.

10. Geroulakos G, Botchway LT, Pai V, Wilkinson AR, Galloway JM. Effect of carotid endarterectomy on the ocular circulation and on ocular symptoms unrelated to emboli. European journal of vascular and endovascular surgery : the official journal of the European Society for Vascular Surgery. 1996;11(3):359-63.

11. Murai S, Kusaka N, Umakoshi M, Itami H, Otsuka S, Nishiura T, et al. Stenting for Internal Carotid Artery Stenosis Associated with Persistent Primitive Hypoglossal Artery Using Proximal Flow Blockade and Distal Protection System: A Technical Case Report and Literature Review. Journal of stroke and cerebrovascular diseases : the official journal of National Stroke Association. 2016;25(6):e98-e102.

12. Li X, Ma X, Lin J, He X, Tian F, Kong D. Severe carotid artery stenosis evaluated by ultrasound is associated with post stroke vascular cognitive impairment. Brain and Behavior. 2017;7(1):e00606. 